\title{
A Study on Leaching Property of Hazardous Substances in Coal Ash Through the Column Test (Percolation test)
}

Jeon TW*, Park JE, Hwang DG, Jeong MJ, Um NI, Kang YY, Shin SK, Hong SY, Lee HS and Jang MJ

National Institute of Environmental Research, Incheon, Republic of Korea

\begin{abstract}
The aim of this study is to identify the characteristics of hazardous substances of coal ash and to evaluate the environmental contamination possibility in order to enable the recycling of coal ash generated in thermal power plants. Currently, the various requirements for the activation coal ash (bottom ash) thermal power plant recycling of emitters and are also required by law to be considered as the country's environmental impact on the environment of large amounts of recycling coal ash. In South Korea's national assembly in requesting an environmental impact if the potential for soil and groundwater that can occur when you recycle roadbed, cover soil of coal ash were performed in this study. Based on this study we intend to develop a plan to expand the use of recycled coal ash. There are 10 coal-fired thermal power plants in Korea. About 8.6 million tons of coal ash was generated from those power plants in 2012. Coal ash is composed of fly ash $(82 \%)$ and bottom ash (18\%). While most of the fly ash is recycled as ready-mix concrete admixtures and cement additives, bottom ash is left unused in landfill located within power plant. So, in this study we assessed the recyclability of the bottom ash generated by Samcheonpo and Hadong thermal power plant. The concentrations of hazardous substances contained in coal ash (bottom ash) were generally lower than criteria for contaminants in soil and standard for hazardous substances contained in designated waste. Result of column leaching test for potential environmental impact assessment indicated that increased leaching led to reduced ionic strength of coal ash. Heavy metals did not show any clear pattern of decreased concentration; however the level of heavy metals in coal ash was generally low. Ecological toxicity in the effluent from column was the level of wastewater disposal criteria (2TU) of Korea, which is judged to be not concerned level in environmental aspects.
\end{abstract}

Keywords: Coal ash; Bottom ash; Percolation test; Leaching pattern; Recycling; Heavy metals; Wastewater disposal criteria

\section{Introduction}

Coal ash is generated after combustion of coal or anthracite in $1,600^{\circ} \mathrm{C}$ in thermal power plants, separated by fly ash and bottom ash [1]. Due to the thermal power plants and cogeneration facilities such as coal ash generation capacity expansion is a trend that continues to grow each year. The world coal ash emissions in 2010, according to the world coal association statistics is about 7.8 billion tons. No.1 China 395 million tons, second largest in North America 118 million tons, $3^{\text {rd }}$ India 105 million tons, $4^{\text {th }}$ has been reported to occur in Europe, 52.6 million tons [2]. In the case of South Korea, there are 10 coalfired thermal power plants in Korea. About 8.6 million tons of coal ash was generated from those power plants. Coal ash generated in Korea has been mainly limited to the consumption of cement or concrete. However in most cement manufacturer portion is left because of the economic problems. However, the thermal power plants of various countries, including the United States and Europe has been continuously developed and applied to a variety of recycling methods and environmentally friendly processing techniques for utilizing coal ash [3]. In domestic power plant generation is to offer a variety of needs for the activation of the coal ash recycling, whereby the environmental impact study that could occur with use of a large amount of coal ash is a situation that is desired. It is possible to recycle coal ash as soils such as covering in some areas and products such as cement and concrete. In this study, we evaluated the recyclability of the soil of these; in particular, we evaluated the environmental impacts such as groundwater and soil in an environmental standpoint. To this end, in the study confirmed that the harmful substances contained in the coal ash characteristics, and coal ash was investigated the change of the harmful substances in the elution pattern when use is mixed with soil. Through this study was to evaluate the environmental impacts due to recycling of the soil.

\section{Materials and Methods}

The samples were collected from Samcheonpo thermal power plant (hereinafter, bottom ash generated in S plant called "S-BA") and Hadong thermal power plant (hereinafter, bottom ash generated in $\mathrm{H}$ plant called "H-BA"). Coal ash used in the two thermal power plants is mainly imported from Indonesia, Australia, Canada, Russia and China. Approximately $10 \%$ of the coal used is generated in coal ash, $80 \%$ of which are captured by the electrostatic precipitator fly ash, the remaining $20 \%$ is deposited on the boiler bottom in the form of flooring. Bottom ash (2\%) is mixed with a large amount of sea water (98\%) transported to the landfill through the pipe line. There are 2 landfills in $\mathrm{H}$ thermal power plant and 6 landfills in $\mathrm{S}$ thermal power plant for coal ash. Approximately 190 million tons of coal ash landfilled in Hadong power plant and Samcheonpo power plant are expected to be used in Y area (Youngam, Jeollanam-Do) as horizontal drain cover soil in the future. Therefore, soil samples of $\mathrm{Y}$ area were also collected in order to examine of the contamination characteristics when mixing with coal ash.

To determine the physical characteristics of the coal ash, net density, porosity and particle size was analyzed. Net density was measured in the defense A $21340 \mathrm{M}$ company has to apply the test method ASTM

*Corresponding author: Tae-Wan Jeon, National Institute of Environmental Research, Incheon, Republic of Korea, Tel: 032-560-7915; E-mail: jeonsa@korea.kr

Received August 21, 2015; Accepted February 29, 2016; Published March 04, 2016

Citation: Jeon TW, Park JE, Hwang DG, Jeong MJ, Um NI, et al. (2016) A Study on Leaching Property of Hazardous Substances in Coal Ash Through the Column Test (Percolation test). J Environ Anal Toxicol 6: 354. doi:10.4172/2161-0525.1000354

Copyright: @ 2016 Jeon TW, et al. This is an open-access article distributed under the terms of the Creative Commons Attribution License, which permits unrestricted use, distribution, and reproduction in any medium, provided the original author and source are credited. 
D6226 porosity was analyzed using A 49500 instruments. In addition, particle size analysis using the B instrument by C LS 13320 by the method according to the laser diffraction and scattering in accordance with ISO 13320 was measured in a dry process. Analysis of hazardous materials in coal ash was carried out in accordance with waste standard test method and soil pollution standard test method of Korea. That is Content analysis of Coal ash was Korea soil pollution test method, leaching analysis was tested according to the Korea waste test method. Lead, cadmium heavy metals such as ICP-OES, AAS was analyzed, after pretreatment with hydrochloric acid and nitric acid. Hexavalent chromium, cyanide, fluoride and pre-treatment were then measured by UV/VIS instrument. Mercury was analyzed by mercury only precision equipment (NIC MA-3000). Analysis of ionic species in the column eluate according to the water pollution standard test method of Korea to pass through the sample to $0.2 \mu \mathrm{m}$ membrane filter paper to remove the soil particles is passed through an anion exchange column and separating each of negative ions measured by a electrical conductivity measuring instrument. Using water flea acute toxicity evaluation samples in the Daphnia in a test solution is diluted by percentage and by observing the streamer state 24 hours after the sample concentration with lethal or swimming the ecotoxicity values through correlation with Daphnia number it seems to inhibit was calculated. Column leaching tests (percolation test) were designed to comply with DIN 19528 methods [4-6]. For a more precise environmental impact assessment, the device was tested by making a size twice the size of what suggested in the test method. Heavy metals, ion substances and ecotoxicological assessment of the column eluent were analyzed according to the water pollution standard test method of Korea.

\section{Results and Discussion}

Table 1 shows the concentration of hazardous material of coal ash. Concentration of coal ash hazardous substances showed a low level compared to the standard soil pollution and waste hazardous substances standards. $\mathrm{CN}$ has been detected at the same level with soil pollution concern criteria of area 2; however the leaching results were not detected. According to the concentration of heavy metals in the coal ash of India, the total chromium concentration is $54 \sim 74 \mathrm{mg} /$ $\mathrm{kg}$, lead is $84 \sim 182 \mathrm{mg} / \mathrm{kg}$, zinc $29 \sim 44 \mathrm{mg} / \mathrm{kg}$, copper $40 \sim 50 \mathrm{mg} / \mathrm{kg}$, nickel $26 \sim 32 \mathrm{mg} / \mathrm{kg}$ [7,8] (Figure 1).

To an environmental impact possibility evaluation of coal ash, alone or in combination with soil column test was performed. Influents using a column test are water, acid precipitation ( $\mathrm{pH} 4.5)$ and distilled water [9]. Elution pattern confirmed by analyzing of the electrical conductivity, ion substances in each eluent as shown in Figure 2. As shown in Figure 2, the more the influent flow tended to electrical conductivity decreases markedly, in other words showed a high correlation between the flow amount and ions. On the other hand, heavy metals did not show a clear pattern in accordance with the flow amount. In case of iron, a low concentration was detected in the initial eluate and then high concentration was detected since 6th Fraction and decreased again at $12^{\text {th }}$ fraction. Ionic substances in the eluate showed a pronounced tendency to decrease according to the flow amount, such as electrical conductivity elution pattern. Mainly detected ion substances were chloride ion, sodium ion, sulfate ion and magnesium ion, which are the main component of the sea water, was detected in high concentrations in the initial eluent and decreased gradually after.

Toxicity levels showed different depending on the incoming water. In other words, showed that receives influent influence than the toxicity of coal ash itself. The ecotoxicity criteria of Industrial wastewater discharge facilities of Korea, wastewater treatment plant of Delaware, New York and Germany is 2 TU. According to the analysis results showed that all eluent remain below $2 \mathrm{TU}$ since second fraction.

Figure 3 did not show any significant reduction in flow characteristics of the resulting overall confirming the dissolution pattern of the various heavy metals contained in coal ash, as shown in. In the case of low Iron concentrations detected in the initial eluate after starting 6 fraction high concentration it was decreased outflow since 12 fraction. In particular the $S$ coal ash alone, the maximum value detected S coal ash column and the 11 fraction in the soil and leaching solution by mixing these characteristics clearly shown in the column test was reduced after being used. Boron is generally tended to decrease as compared to other heavy metals compared to coal ash alone column with soil mixed with the boron concentration in the eluate of the column is significantly lower. Aluminum, manganese, nickel, antimony, selenium, cadmium, etc. in addition to the analysis of heavy metals items did not show a specific trend, copper, lead, zinc, hexavalent chromium, mercury was not detected in both effluent. In addition, eluent in accordance with the results of acute toxicity tests using the water flea inflow toxic level showed different. That is, rather than the toxicity of coal ash itself water, fresh water, and it is determined to be affected by acidic precipitation, such as influent.

\section{Conclusion}

Concentration of coal ash hazardous substances showed a low level in all items. According to the columns of the dissolution test results for the environmental impact evaluation, as the inlet quantity increasing amount of ions is decreased. The coal ash environment was evaluated for potential effects that may occur in the process of recycling as the soil and compared groundwater quality standards according to the guideline of United States [10]. As a result, the effect of heavy metals was determined to be low. However, it was determined that chloride ion and sulfate ion are likely to have a high impact on the environment. Therefore, it was determined to be necessary for the proper handling and management of ionic substances in the course of recycling of coal

\begin{tabular}{|c|c|c|c|c|c|c|c|c|c|c|c|}
\hline \multicolumn{2}{|c|}{ Items } & \multirow{2}{*}{$\begin{array}{c}\text { Cd } \\
7.83\end{array}$} & \multirow{2}{*}{$\begin{array}{c}\mathrm{Cu} \\
4.50\end{array}$} & \multirow{2}{*}{$\begin{array}{c}\text { As } \\
2.38\end{array}$} & \multirow{2}{*}{$\begin{array}{l}\mathrm{Hg} \\
\text { N.D. }\end{array}$} & \multirow{2}{*}{\begin{tabular}{c|}
$\mathbf{P b}$ \\
2.80
\end{tabular}} & \multirow{2}{*}{$\begin{array}{l}\mathrm{T}-\mathrm{Cr} \\
4.20\end{array}$} & \multirow{2}{*}{$\begin{array}{l}\mathrm{Cr}^{6+} \\
\text { N.D. }\end{array}$} & \multirow{2}{*}{$\begin{array}{c}\mathrm{Zn} \\
11.50\end{array}$} & \multirow{2}{*}{$\begin{array}{c}\mathbf{N i} \\
5.10\end{array}$} & \multirow{2}{*}{$\begin{array}{l}\mathbf{C N} \\
1.30\end{array}$} \\
\hline Content & S-BA & & & & & & & & & & \\
\hline \multirow[b]{2}{*}{$(\mathrm{mg} / \mathrm{kg})$} & H-BA & 2.15 & 8.30 & 4.90 & 0.13 & 2.00 & 5.50 & N.D. & 13.70 & 7.80 & 2.00 \\
\hline & Soil & 2.89 & 20.6 & 12.52 & 0.13 & 14.2 & 52.8 & 0.8 & 48.5 & 16.4 & 0.4 \\
\hline \multirow{3}{*}{$\begin{array}{l}\text { Leaching } \\
\text { (mg/L) }\end{array}$} & S-BA & N.D. & N.D. & N.D. & N.D. & N.D. & - & N.D. & - & - & - \\
\hline & H-BA & N.D. & N.D. & 0.003 & N.D. & N.D. & - & N.D. & - & - & - \\
\hline & Soil & N.D. & 0.061 & 0.137 & N.D. & N.D. & - & 0.01 & - & - & - \\
\hline
\end{tabular}

ND: Not Detected 

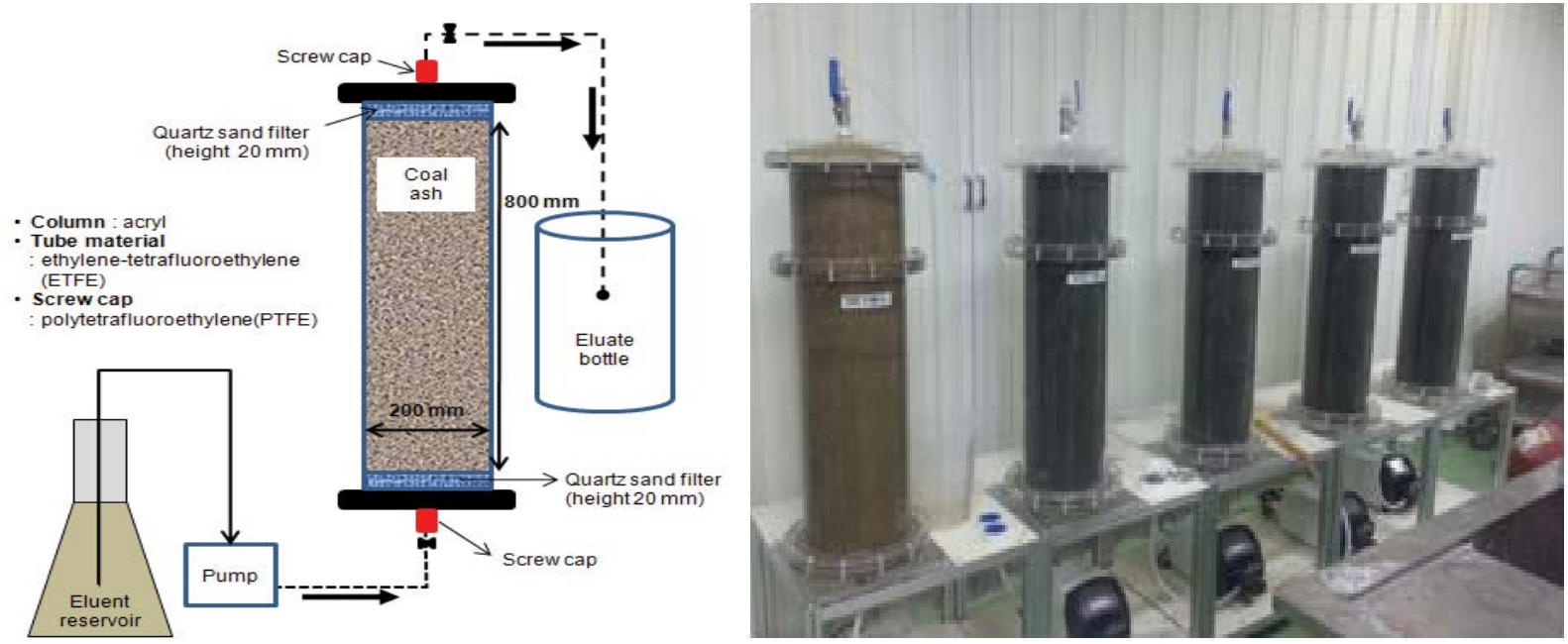

Figure 1: Diagram and picture of column test (percolation test).
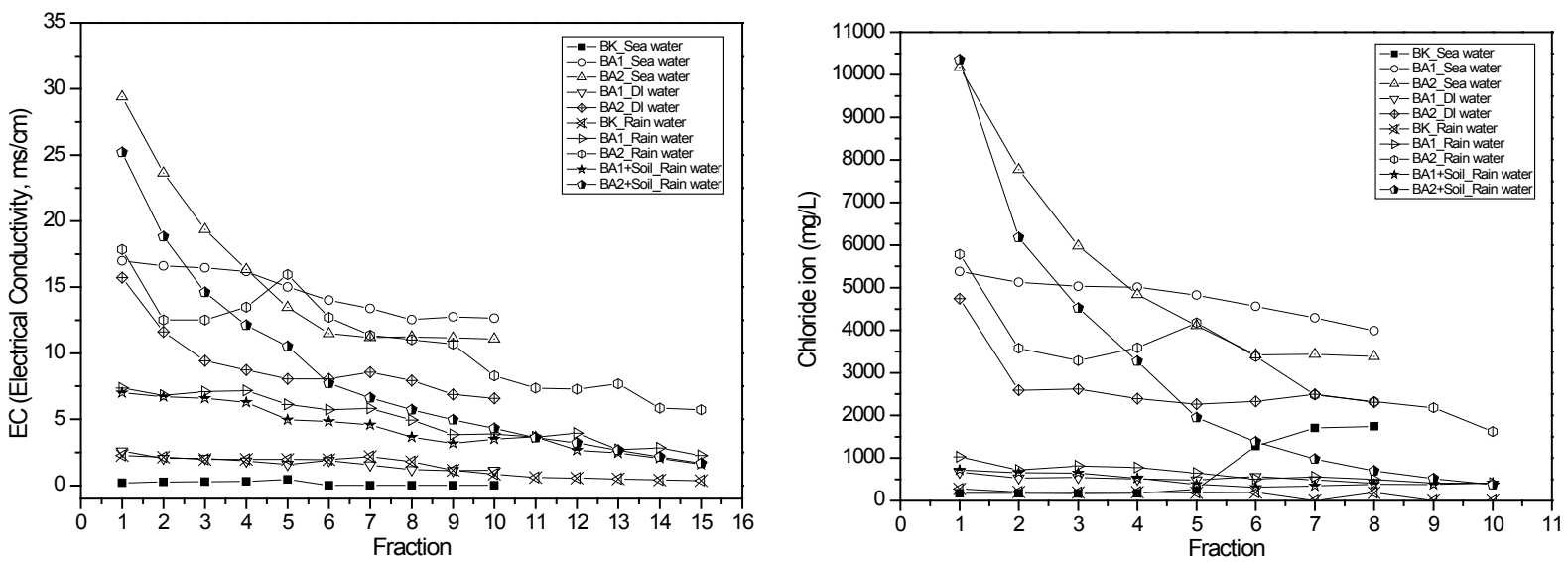

Figure 2: Electrical Conductivity and $\mathrm{Cl}$ release pattern of leachate by column percolation test.
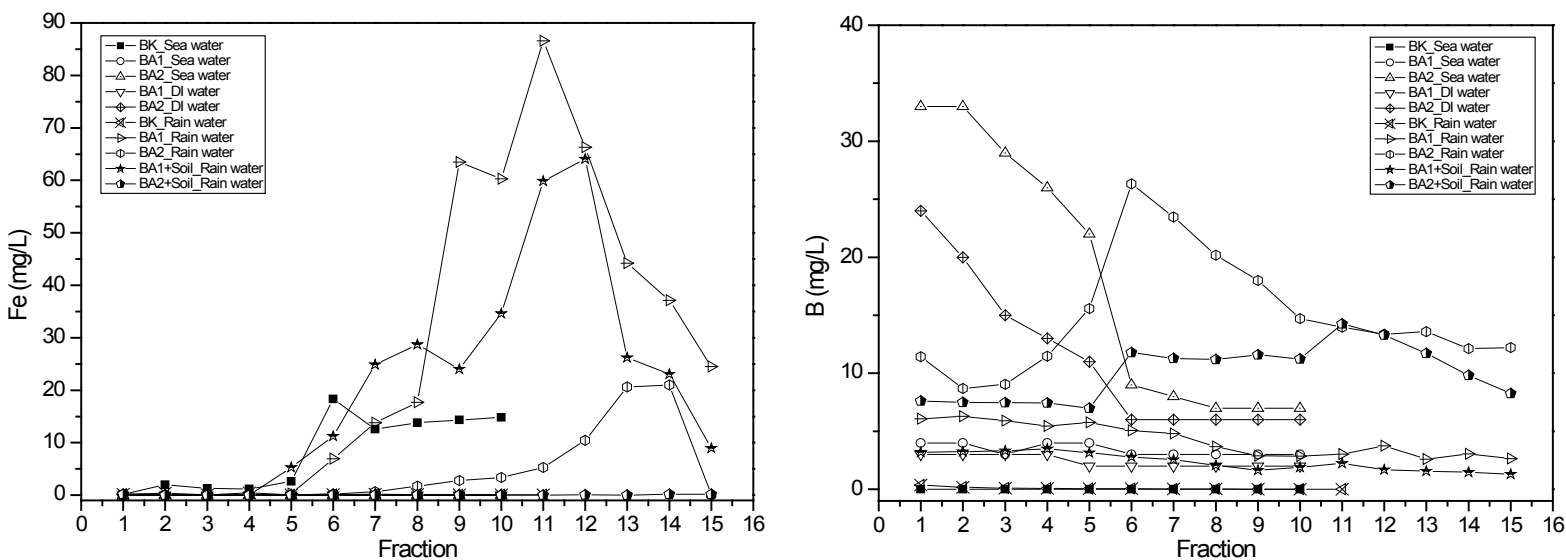

Figure 3: Fe and B release pattern of leachate from column percolation test.

ash. The acute toxicity of the column effluent using the water flea was confirmed through experiments. Results seawater, fresh water, acid rain etc., depending on influent toxicity level is different than likely affected the inflow of toxic coal ash (bottom ash) itself. Eluent appeared to be the result of varying levels, depending on influent toxicity was starting after confirming the ecotoxicity of 2 fractions from all columns appeared to remain below industrial waste water emission standards (2TU). 
Citation: Jeon TW, Park JE, Hwang DG, Jeong MJ, Um NI, et al. (2016) A Study on Leaching Property of Hazardous Substances in Coal Ash Through the Column Test (Percolation test). J Environ Anal Toxicol 6: 354. doi:10.4172/2161-0525.1000354

Page 4 of 4

\section{References}

1. National Institute of Environmental Research (Korea NIER) (2011) Study on mixture of coal ash and soil.

2. WCA (2012) World Coal facts 2012. World Coal Association.

3. Craig H, Hans-Joachim F, Anne W (2013) Coal combustion products: a global perspective. 2013 World of coal Ash Conference, Lexington, KY, pp: 22-25.

4. Germany Standardization Organization (2009) DIN 19528: Percolation method for joint examination of the leaching behaviour of organic and inorganic substances for materials with a particle size upto $32 \mathrm{~mm}$-basic characteristics using a comprehensive column test and compliance test using a quick column test.

5. Sakanakura H, Osako M, Kida A (2009) Effect of exposure test conditions on leaching behavior of inorganic contaminants from recycled materials for roadbeds. Waste Manag 29: 1658-1665.
6. DIN 19528 (2013) Elution von festst offen-leaching of solid materialspercolation method for the joint examination of the leaching behavior of organic and inorganic substances for materials with a particle size up to $32 \mathrm{~mm}$.

7. Snigdha S, Vidya SB (2006) Analysis of fly ash heavy metal content and disposal in three thermal power plants in India. Fuel 85: 2676-2679.

8. Praharaj T, Powell MA, Hart BR, Tripathy S (2002) Leachability of elements from sub-bituminous coal fly ash from India. Environ Int 27: 609-615.

9. Alper B, Abidin K (2004) Leaching characteristics of solid wastes from thermal power plants of western Turkey and comparison of toxicity methodologies. $J$ Environ Manage 73: 199-207.

10. United State Environmental Protection Agency (USEPA) (2006) State regulation of fly ash use in subbase stabilization and fill for highway construction in the Minnesota region. 